\title{
Having Social Practices in Mind.
}

Wittgenstein's Anthropological Pragmatism in Perspective

\section{Francesco Callegaro}

\section{CpenEdition}

\section{Journals}

Electronic version

URL: http://journals.openedition.org/ejpap/730

DOI: $10.4000 /$ ejpap.730

ISSN: 2036-4091

Publisher

Associazione Pragma

\section{Electronic reference}

Francesco Callegaro, « Having Social Practices in Mind. », European Journal of Pragmatism and American Philosophy [Online], IV-2 | 2012, Online since 24 December 2012, connection on 30 April 2019. URL : http://journals.openedition.org/ejpap/730 ; DOI : 10.4000/ejpap.730

This text was automatically generated on 30 April 2019

\section{(c) $($ ) $\odot$ (8)}

Author retains copyright and grants the European Journal of Pragmatism and American Philosophy right of first publication with the work simultaneously licensed under a Creative Commons AttributionNonCommercial-NoDerivatives 4.0 International License. 


\title{
Having Social Practices in Mind.
}

\author{
Wittgenstein's Anthropological Pragmatism in Perspective
}

\author{
Francesco Callegaro
}

\section{Introduction}

As Wittgenstein says in a well-known paragraph of the Investigations, commenting St. Augustine's question on time, it belongs to the "essence" of a philosophical inquiry that "we do not seek to learn anything new by it," only to "understand something that is already in plain view": philosophy deals with what is already known, but somehow forgotten, something, therefore, "that we need to remind ourselves of" (PI, § 89). Thus, if there is something new in philosophy, it is not, as in science, a discovery going beyond evident and common experience, but the rediscovery of "the phenomena of everyday," as St. Augustine says in a passage quoted by Wittgenstein later: "Manifestatissima et usitatissima sunt, et eadem rursus nimis latent, et nova est inventio eorum" (PI, § 436). Like an orator, the philosopher must find out the metaphorical language capable of shedding a new light on common places, thus making the forgotten evidence of ordinary phenomena shining again. If this is the task Wittgenstein assigned to philosophy, I think he has fulfilled it, first and foremost, by developing a language that opens us to a new understanding of what we are. Indeed, presupposed by and developed through all his grammatical remarks, removing our philosophical prejudices on a given topic, lies a fundamental image calling back to mind what it means and is needed for us to have a mind at all. Since we all spontaneously are, in our reflective attitudes toward ourselves, awfully Cartesians, even when we think we are empiricists, Wittgenstein's new image can be summed up by two major shifts. The first is a move from internal, mental cognition to external, expressive action, whether linguistic or not. The second is a move from an isolated, self-sufficient individual to a related, essentially dependent member of a community. Putting these two moves together, we could say that Wittgenstein tried to remind us that we owe what we are to the existence of social practices. It is this anthropological perspective, lying at the heart of his second philosophy, which becomes 
fully explicit in On Certainty: there Wittgenstein finally acknowledges, somewhat bewildered, that, by stressing the primacy of socially instituted action as the entry and basis of language games, he is putting forward a perspective "that sounds like pragmatism" (OC, § 422). The aim of this paper is to clarify what, if anything, sounds like "pragmatism" in Wittgenstein's conception of mind and meaning as being grounded in social practices.

2 To this end, I will not look backward at the criteria of use fixed by the inventor of the word, C. S. Peirce, or by his immediate followers, James and Dewey, ${ }^{1}$ but rather replace Wittgenstein's animating idea in the context of contemporary debates, which are reshaping the very meaning of 'pragmatism.' I will focus, in particular, on R. Brandom's attempt to understand Wittgenstein's philosophy as belonging to an intellectual tradition from which his own rationalist pragmatism should be seen as deriving. Indeed, by so distinguishing a broad pragmatist framework from the narrower instrumentalist perspective of the American founders, Brandom frees the way for an analysis in which Wittgenstein's own pragmatism can be properly understood. ${ }^{2}$ Instead of looking for local comparisons with the specific tactics of classical pragmatism, which requires endorsing Darwinian naturalism, seeing beliefs as effective means to successful action, while thinking of meaning as being fixed in the experimental context of a fallibilist inquiry, Brandom outlines a more general theoretical strategy, which consists in taking 'discursive intentionality' as springing from a more basic form of 'practical intentionality': the later Wittgenstein and the early Heidegger would belong, together with Dewey, to this 'fundamental pragmatism,' which found in Kant one of its first expressions. ${ }^{3}$ In this general theoretical framework differences can further be explained as ways of accounting for the primordial practical intentionality, according to whether it refers to purposive instrumental action or to expressive, socially instituted interaction, language itself being either a useful tool for survival or the paradigmatic form of a socially instituted expressive interaction.

3 Brandom's re-appropriation of Wittgenstein's fundamental pragmatism focuses, in the opening pages of Making It Explicit, on a close reading of the rule-following argument. This is where a critical confrontation should take place, which can help us pointing out the specific tactics of Wittgenstein's pragmatism. Indeed, if Brandom's reading clarifies Wittgenstein's central idea of social practices, by making the structure of the argument explicit and by developing its consequences through a systematic discussion of its possible developments, it must be admitted, at the same time, that the rationalist pragmatism he elaborates on this basis deeply departs from Wittgenstein's own pragmatist perspective. This is because Brandom's reading is ultimately rooted in his commitment toward the rationalist tradition of German idealism, which he now sees as the true origin of American pragmatism to which we should return: thus, just as Sellars used Wittgenstein to answer to some of peculiar problems of the rationalist tradition, ${ }^{4}$ Brandom takes up Wittgenstein's conception of social practices to socialize Kantian philosophy of mind, embracing, as a result, a renewed Hegelian philosophy. This is the perspective of Brandom's reading: his discussion of the rule-following argument is a dialogue between Kant and Wittgenstein whose result must be Hegel, at least his own reading of Hegelian idealism. Bearing in mind Brandom's formula -Kant +Wittgenstein=Hegel - his whole strategy can be reduced to one single argument, which will give us the right point of entry for a critical confrontation with Wittgenstein. The argument is the following: 
1: Concepts express rules. (This is Wittgenstein after Kant);

2: Rules express normative social practices. (This is Kant after Wittgenstein);

3: Concepts express normative social practices. (This is Hegel, in Brandom's reading).

4 The conclusion of the argument is the starting point of Brandom's rationalist pragmatism, according to which the game of giving and asking for reasons is the normative social practice that articulates concepts. If we want to resist this rationalist conclusion and rediscover Wittgenstein's pragmatism understanding of what we are, we must critically examine the two premises. McDowell has recently argued, from a supposedly Wittgensteinian perspective, against Brandom's reconstruction of the rulefollowing argument, whose conclusion is stated in the second premise: thus, I will first present, discuss and defend Brandom's reading, trying to explain why his discussion offers us an interesting philosophical contribution which enables us to understand the meaning and justification of Wittgenstein's animating idea of social practices. Following some key suggestions of V. Descombes, I will then argue that it is rather the very Kantian framework, grounding Brandom's as well as McDowell's understanding of the first premise, which should be rejected, since it is indifferent to the difference of normative vocabularies that Wittgenstein constantly underlined in order to articulate the irreducibility of grammatical rules. Having questioned the continuity between Kant and Wittgenstein, I will be able to conclude by uncovering the structural features of Wittgenstein's anthropological pragmatism.

\section{Rules Express Normative Social Practices: Brandom's Reading of Wittgenstein's Argument}

\section{The Structure of the Argument}

In order to see how Brandom reconstructs the whole discussion on rule-following, it is useful to start at the end, by a sketchy description of the very phenomenon which is supposed to be there, under our eyes, in the manifest light of everyday life, if it was not obscured by bad philosophical theorizing that must be refuted to understand it fully. Let us take Wittgenstein's example: while driving in the street, we have no doubts about the way indicated by a sign-post (See PI, § 85). The somewhat puzzling aspect of what would otherwise seem to be a perfectly obvious phenomenon is that we spontaneously follow what has nonetheless to be taken as a rule: the very possibility of describing our intentional action presupposes both a distinction between what the rule says and what we actually do, on one side, and our effective capacity to follow it, on the other. The starting phenomenon has, therefore, these two constitutive dimensions: ${ }^{5}$

- Practical-psychological dimension: the rule governs our behavior effectively, through our understanding of it.

- Prescriptive-epistemic dimension: the rule dictates the following step and it is by reference to the rule that we justify our step as the right one.

According to Brandom, the melody of Wittgenstein's argument follows this theme: philosophical theories, trying to explain the original phenomenon of rule-following, give an account of only one side of it, while we have to explain both. This is why Brandom focuses on two opposed perspectives. The first is too much struck by the prescriptive nature of rules: regulism is the general philosophical perspective according to which explicit rules, intellectually grasped, govern our intentional behavior. Wittgenstein helps us refuting it 
through a regress argument, showing that, unless one already knows how to apply a rule correctly, a regress opens up, concerning the right application of the rule telling us which is the right step to make. This argument shows the immediately practical side of rulefollowing. The second philosophical account is then too much struck by the practical nature of rules: regularism is the general philosophical perspective according to which rules are nothing but generalized regularities read off from our actual behavior. Wittgenstein helps us refuting it through the gerrymandering argument, showing that a normative rule cannot be derived from a set of observed regularities since any sequence of steps can be read retrospectively as following a given rule. This argument shows the necessary prescriptive side of practical rule-following, which cannot be accounted for without seeing its social nature. Hence, the idea of social practices as the result of Wittgenstein's critical refutation of traditional accounts. To discuss the details of Brandom's reconstruction, and to see if and how he understands Wittgenstein, it is useful to start by answering to McDowell's objections.

\section{Against Regulism}

6 According to McDowell, Brandom would have missed the whole point of Wittgenstein's argument: throughout the discussion on rule-following, there would be not two but "only one master argument," showing the bad consequences of the "temptation" to open a "conceptual gap between the expression of a rule and performances that are up for assessment according to whether or not they conform to the rule" (2009: 108-10). The problem would not be the rules' explicit nature but the fact that they are signs which, unless one already understands them, would need an extra meaning-giving interpretation opening a disastrous regress of interpretations. Beyond the regress of interpretations, Wittgenstein would therefore rediscover the immediate understanding of signs. According to McDowell, the argument ends here. Regulism is "simply irrelevant" (2009: 99) to Wittgenstein's reflections on rule-following, since "nothing is done," in his philosophy, to conceive "a level of normativity below that at which correctness can be conceived as conformity to rules" (2009: 110). Now, despite the existence of a more fundamental regress of signs, which occurs elsewhere in Wittgenstein, for instance in the Blue Book, ${ }^{6}$ it is enough to go back to one the first movement in the rule-following sonata to see why these two claims are simply wrong.

7 In $\$ 81$ we find a seminal discussion on the normative nature of language. Commenting Ramsey's assertion on logic as a normative science, Wittgenstein explains it through the game comparison. In philosophy "we often compare the use of words with games and calculi which have fixed rules": the problem is how to keep the idea of a normative dimension in language, linked to logic, without saying that our languages only "approximate" an "ideal language"; the only way out is to try to understand understanding: "For it will then also become clear what can lead us (and did lead me) to think that if anyone utters a sentence and means or understands it he is operating a calculus according to definite rules" (PI, § 81). Wittgenstein wants, therefore, to free us from the idea of understanding as following fixed, definite rules. This is why he asks: "What do I call 'the rule by which he proceeds?" (PI, § 82). He distinguishes, then, three kinds of rules. The first kind is the rule conceived as a "hypothesis" explaining regular observed behavior, while the second is the one an individual "looks up when he uses signs" or "the one which he gives us in reply if we ask what his rule is": if the first is the rule as regularity, the second 
is the explicit rule; but Wittgenstein is interested in the possibility of not finding an answer, either through "observation" or by "question": the problem is then to know what "meaning" the expression "the rule by which he proceeds" (PI § 82) could still have. Now, the very point of the "analogy between games and language" is to "throw light" (\$ 83) on this problem of a more than regular, norm-governed behavior, yet not entirely covered by explicit rules. Thinking of language through the language-game metaphor helps us seeing that "the application of word is not everywhere bounded by rules" (PI, § 84). Here "rules" must mean explicit, that is, fixed and definite, rules. This is why we find here a first formulation of the regress argument, taken up by Brandom: "But what does a game look like that is everywhere bounded by rules? [...] Can't we imagine a rule determining the application of a rule, and a doubt which it removes - and so on?" (PI, § 84). ${ }^{7}$ This is the point from which Wittgenstein comes to the concrete metaphor of the sign-post, saying: "A rule stands there like a sign-post" (PI, § 85). Wittgenstein wants here to make clear that normative behavior should be conceived first with this example in mind. We know how to deal with a sign-post, despite the fact that a lot of questions could be asked, questions concerning even its meaning, this is why he asks: "But where is it said which way I am to follow it" (PI, § 85)? A simple, spontaneous answer could be: in the rules of the road, in the same way as the meaning of the king in chess is fixed "in the list of the rules of the game" (PI, § 197). There is no philosophical account in this answer, because there is no philosophical problem to answer to. The philosophical debate starts when, forgetting our know-how, we start thinking to rule-following exclusively in terms of following an explicit rule. This is regulism. As Brandom says, it is against this "intellectualist, Platonist conception of norms" according to which "to asses correctness is always to make at least implicit reference to a rule or principle that determines what is correct by explicitly saying so" that Wittgenstein's regress of application argument is directed: it shows that "explicit rules do not form an autonomous stratum of normative statuses," but "rest on properties governed by practice" (1994: 20). The point is not one of reduction, but of conceptual priority: "Norms that are explicit in the form of rules presuppose norms that are implicit in practices" (ibid.).

\section{Understanding Practical Understanding}

8 The conclusion of the first part of the argument can be stated as follows: to have the prescriptive side of a rule, one must first acknowledge its internal link with practice. Thus, even if there are explicit rules codifying signs, as with chess rules, the connection between rules and actions, as Wittgenstein says, cannot be made unless one adds "the day-to-day practice of playing" (PI, § 197). ${ }^{8}$ Knowing a rule is the practical understanding which consists in knowing how to follow it. This is what Wittgenstein means when he says that "the grammar of the word 'knows' is evidently closely related to that of 'can', 'is able to.' But also closely related to that of 'understands.' ('Mastery' of a technique)" (PI, § 150). Here lies a first pragmatist commitment in Wittgenstein's picture. We cannot stop here, however, since a problem remains: how should we conceive, indeed, the relation between the actual behavior and the rule, if the latter has to preserve its prescriptive nature?

9 According to McDowell, Wittgenstein has an answer to this question. Yet, since, according to his reading, there is only one master argument, he can state it only as a supposed evidence: "Of course the practice with sign-post is essentially norm-involving" (2009: 105). Actual understanding is not, therefore, a "mere uncomprehending disposition to 
react to what are in fact sign-posts in 'appropriate' ways" (2009: 101). Furthermore, when we ask how practice can be normative in this way, McDowell answers once again with a supposed evidence: "Of course not everyone who encounters a sign-post gets told which way to go. Sign-posts do not speak to those who are not party to the relevant conventions" (2009: 101). McDowell makes, therefore, two related, although unwarranted, steps after the first conclusion of the rule-following argument: practice is normative and it is normative because it is social. Now, if this has to be Wittgenstein's image, it might be interesting to know why. After all, one has only to think to those who argued, like Kripke, that practice is social, but for this very reason not normative, and those who answered him by saying that practice is normative, but for this very reason not social. Brandom's discussion of regularism can be helpful here, since it shows, against these two readings, the necessity of the two steps that McDowell invites us to make without giving us good reasons to do it.

\section{Against Regularism}

Regularism resolves the problem of the relation between actual behavior and rules by thinking of rules as hypothesis read off from actual behavior, according to the first of the three conceptions of rules that Wittgenstein discusses in $\$ 82$ we have seen above. Brandom develops it through a reading of Sellars, who elaborated a scenario we already find in Wittgenstein: "we say that [a game] is played according to such-and-such rules because an observer can read these rules off from the practice of the game - like a natural law governing the game" (\$ 54$)^{9}$. In this framework we have, on one side, an agent displaying regularities in behavior with the aid of the relevant dispositions, and, on the other, an observer, trying to extract the rules to which the agents is implicitly conforming to. Now, what Brandom labels the gerrymandering argument, taken from Kripke's reading of Wittgenstein, ${ }^{10}$ is the inevitable consequence of the confusion between norms and laws implicitly pointed out by Wittgenstein. Indeed, once we presuppose that rules are explanatory hypothesis, not only nothing can prevent us but we are even obliged to modify previously made generalizations in light of new behavior, in such a way that there is no more any way of distinguishing between correct and incorrect actual behavior. Rules as explanatory hypothesis describe natural dispositions, while we were looking for rules governing normative dispositions.

11 The fundamental lesson is, according to Brandom, a Kantian one: "Kant takes it that everything in nature happens according to rules. Being subject to rules is not special to us [...] What is distinctive about us is the way in which we are subject to norms (for Kant in the form of rules). As natural beings we act according to rules. As rational beings, we act according to our conceptions of rules" (1994: 30). This is a general point about the normative nature of intentional behavior that Wittgenstein has inherited from Kant, through Frege, while helping us overcoming Kant's fixation on explicit rules. ${ }^{11}$ The problem is therefore to see how our own representations can single out regularities as the normatively relevant ones, so as to make a distinction, at the level of practice, between what happens and what ought to happen. To put the point in Wittgenstein's own words, we need to understand how a "practice" can be a way of "grasping a rule" (PI, §§ 201-2). In order to find an answer, we must follow the question Wittgenstein asks himself after having imagined the possibility of an observer extracting the rule from actual behavior: "how does the observer distinguish [...] between players' mistakes and correct play?" (PI, 
$\S 54)$. This is the question we have to answer if we want to give a prescriptive force to the rules emerging from actual behavior.

\section{From Individual Behavior to Social Practice}

12 A first strategy would be to take Wittgenstein's own suggestion seriously: there are "characteristic signs" of the normative distinction between behavior and norm "in the players' behaviour. Think of the behaviour characteristic of correcting a slip of tongue" (PI, § 54). Although Brandom consecrates only a footnote to such a perspective, ${ }^{12}$ it deserves to be discussed in detail, since this is what Hacker and Baker think Wittgenstein was after. According to their reading, if we add self-correcting behavior to actual behavior we have, as they say, "regularities of action complex enough to produce norms." ${ }^{13}$ Self-correcting behavior would be, therefore, the only missing element to bridge the gap between rule and behavior: through it, an agent would prove his sensitivity to norms, rules being the objective dimension hidden in his complex actual behavior. Wittgenstein would not endorse, therefore, social readings of practices: what we have here is public evaluable behavior, but an isolated individual, like Robinson Crusoe, could do this all by himself. The problem of this answer is that it smuggles a fundamental normative distinction into an account that it is supposed to be free of it. Indeed, for observed regular behavior to produce norms one needs to conceive the self-correcting behavior as more than mere self-observation, otherwise the gerrymandering problem occurs again at the level of self-correction, which itself open to an evaluation. Self-correction must be, therefore, the manifestation of judging oneself in light of a previously given norm: the right couple, so to speak, is not that of an agent and an observer, but that of an agent and a judge. Now, unless we go back to regulism, thinking that the agent has access, when judging, to a pre-established rule containing all its applications, we have to think of selfcorrecting behavior as the manifestation of a practical sanctioning disposition interiorized from an external, previously existing, social relation.

This is why Brandom moves directly toward theories that reconstruct Kant's distinction between rules as natural laws and rules as conceived norms in the frame of a "social theory," by appealing to the "distinction of perspective between assessing a performance and producing a performance" (1994: 37). A first step in this direction is J. Haugeland's heideggerian analysis of Wittgenstein. ${ }^{14}$ For Haugeland, norms are constituted and manifested in the difference between the dispositions to act of an agent and the dispositions to sanction of a judge: "Haugeland's censorious herd animals shape each other's behavior by their capacity not only to perform but to censure performance. Each animal in the community that is thereby constituted may [...] be able to do both, but as he conceives it, each act of censure involves two organisms, the censuring and the censured" (1994: 37). The naturalistic vocabulary is there to show that the distributed complex behavior is supposed to engender norms without already presupposing explicit rules: the distinction between what is done and what ought to be done is, therefore, entirely dependent upon the dispositions to sanction, which are supposed to manifest sensitivity to norms as such. This perspective does not go, however, deep enough. Indeed, as Brandom points out, since "assessing, sanctioning, is itself something that can be done correctly or incorrectly," one has to make room for the difference between "actually being punished" and "deserving to be punished" (1994: 36). This means that the assessor puts forward, by sanctioning, a claim to authority: sanction, far from establishing authority, presupposes it. 
We have to move, therefore, to what Brandom acknowledges as a "more robust" theory of social practices: the authority of the assessor, far from producing common norms, rests upon the authority of a "communal assessment" (1994: 37). As a matter of fact, this is where Wittgenstein, pace Hacker and Baker, wanted to lead us. Norms cannot be conceived unless they are common (See PI, $\S \S 198,199$ ): from a grammatical point of view, we can indifferently use, as Wittgenstein does very often, "understanding a sign," "using it as we always use it" and "having being taught to use it in such a way" (PI, § 190). Here we have a conceptual network which throws light on the original phenomenon of normative intentional behavior, conceived as expressive action following a social practice after a training period. Wittgenstein thought that this rediscovery of the ordinary was all that philosophy, as a dialectical refutation of bad theorizing, should do. Having another conception of philosophy, Brandom thinks the phenomenon is not yet fully understandable.

\section{The Internal Structure of Social Practices}

Indeed, the move to a community view, despite its necessity, is ever more demanding, since we are now explaining norms through normative notions. On the side of the assessed, we have the problem of "community membership," which is a "normative status": here the circularity is evident, since we explain why someone has to do something in some circumstances by saying that, being a member of the community, he " ought to conform to the norms implicit in the practice of the community" (1994: 39). On the side of the assessors, we have the problem of who is entitled to the authority claim: leaving aside the meaningless solution of the Community as a possible assessor, we face the problem of "experts," those who have "the authority to speak for the community" (1994: 39). Once again this is a normative status, so we are obliged to make "a distinction between actually assessing and being entitled to assess" (1994: 39-40). This twofold problem shows that the reference to the community only shifts the problem: the structure of social practices, based on the "distinction of normative statuses" between "the experts, the ones who have authority" and "those who are subject to that authority" (1994: 39-40), needs to be accounted for.

Thus, if Brandom criticizes the "orienting mistake" of "treating I-We relations rather than I-Thou relations as the fundamental social structure," it is not because it would be a mistake to develop a community view, but because we need substantive theorizing to understand what it means for a community to be there in the first place: now, privileging I-We relation only make us think that there is something other than individuals - The Community - making assessments, whereas "assessing, endorsing, and so on are all things we individuals do and attribute to each other, thereby constituting a community, a "we" (1994: 39). This is where Brandom starts developing a Hegelian perspective. Indeed, at the bottom of the mutual attributions that constitute norms lies the very normative structure making these attributions possible:for common norms to be there in social practices, we need first to think of the attitude of attributing authority, while taking the responsibility to act, and the attitude of attributing responsibility, while taking the authority to judge. As Brandom explained in a later essay, this is, in his view, the "reciprocal structure of authority and responsibility" that Hegel put forward under the heading of "mutual recognition." ${ }^{15}$ It is through this Hegelian conceptual framework that Brandom tries to clarify the social institution of conceptual norms, that is, the possibility for concepts, as socially instituted norms, to incorporate nonetheless, in and by their historical 
development, an objective commitment. Despite the relevance of this possible sociohistorical Hegelian development of Wittgenstein, however, Brandom's philosophical edifice rests on some questionable presuppositions, due to the narrow Kantian way in which he understands conceptual norms themselves.

\section{Concepts Express Rules: Some Wittgensteinian Objections to Brandom's Rationalism}

\section{Brandom's Narrow Kantian Framework}

The whole discussion on rule-following is framed by a general point that Brandom makes in some introductory pages about the normative nature of concepts considered as Kant's main contribution to philosophy. After Kant, he says, the mental has not to be understood, as with Descartes, around the ontological distinction with the physical, but around a deontological distinction with the causal. What thus characterizes us as knowers and agents is our capacity to add conceptual rules to given regularities, whether to know natural necessities or to act upon moral necessities. Understanding this point requires, accordingly, understanding the peculiar Kantian idea of necessity (Notwendikgeit). As Brandom says, the "nature and significance of the sea change from Cartesian certainty to Kantian necessity will be misunderstood unless it is kept in mind that by 'necessary' Kant means 'in accord with a rule"': the Kantian, proto-pragmatist commitment to the "primacy of the practical" for cognitive and practical activity can be understood only by seeing that the "key concept of both is obligation by a rule" in the sense articulated by the "deontic modality of commitment and entitlement, rather than the alethic modality of necessity and possibility" (1994: 10). Further philosophical thought would have only made this Kantian point more clearly by developing the two constitutive dimensions of concepts, truth and inference. Thus, while acknowledging that Wittgenstein developed an original reflection on "the nature of norms," Brandom explains it by making and remaking the same Kantian point: "Many of his [Wittgenstein's] most characteristic lines of thought are explorations of the inaptness of thinking of the normative 'force' which determines how it would be appropriate to act on the model of a special kind of causal force" (1994: 14). From this point of view, Brandom is naturally led to read Wittgenstein's question "How am I able to obey a rule?" (PI, § 217) in the following way: "it is a question about what actions accord with the rule, are obliged or permitted by it, rather than with what my grasp of it actually makes me do" (1994: 15).

The problem of such a Kantian translation of Wittgenstein's question is easy to miss, since Brandom constantly makes a double move, while believing he is only making one. For, on one side, he is putting forward the very general distinction we saw at work above in the criticism of regularism: to think about a norm, of whatever kind, as opposed to mere regularities, one has to make a distinction between what happens and what must happen according to the rule. Yet in thinking about what must happen, Brandom endorses, at the same time, the moral-legal framework that Kant inherited from modern thought. ${ }^{16}$ Thus, he explains the distinction between "the force of causal 'must's' and "the force of logical or rational 'must's"' invoked by Wittgenstein by reducing it to this more specific framework, in which the "government by norms" essentially requires "the possibility of mistakes, of those subjects to norms going wrong, failing to do what they are obliged by those norms to do": thus, whereas attributions of natural laws are "incompatible" with the idea of not 
conforming to them, attribution of norms requires, according to Brandom, "leaving room" for "mistakes and failures," this being "one of the essential distinguishing features of the 'ought's' that express government by norms" (1994: 30-31, I emphasize). It is clear enough that despite its supposed generality, Brandom's distinction refers to norms capable of sorting out behavior as appropriate or inappropriate, both possibilities being intelligible: the very normative vocabulary of commitments and entitlements refers, indeed, to "the traditional deontic primitives of obligation and permission," freed of the "stigmata they contain betraying their origin in a picture of norms as resulting exclusively from the commands or edicts of the superior, who lays an obligation on or offer a permission to a subordinate" (1994: 160). Thus, if Brandom follows Wittgenstein in criticizing regulism, he only changes the operative level, not the conception, of norms: if rules are norms implicit in practice, they are still conceived as obligations, prohibitions and permissions. It is this narrow conception of normativity, and therefore of concepts, which must be criticized from a Wittgenstenian perspective. I will follow here V. Descombes, who has recently argued that this Kantian reading of Wittgenstein misses the very point of his whole philosophy. ${ }^{17}$ This will help us pointing out the fundamental tactics of Wittgenstein's pragmatism.

\section{Kinds of Rules}

17 According to Descombes, one cannot understand Wittgenstein's discussions on rules unless one sees that the main contrast orienting his philosophy, after the Tractatus, was not the one between causal regularities and rational obligations but that between causal and logical impossibilities, or necessities. To understand this difference, let us take Wittgenstein's example: "it is impossible for a human being to swim across the Atlantic" (1958: 54). Here the incompatible assertion - a human being can swim across the Atlantic - is perfectly intelligible: as Descombes points out, the failure depends on our physical capacities, so that "we can understand what it would mean to succeed" and even "try one's luck" (2007: 402) against what the assertion says it is impossible to do. This is not the case with logical impossibilities. The "logical obstacle" is not, as Descombes says, a "hyperphysical obstacle," since here we do not even understand what it would mean to overcome it: what Wittgenstein wanted to underline with this contrast was, therefore, that logical impossibilities do not concern human "finitude," but the conditions of “meaning" (2007: 402-3).

18 The peculiar nature of the normative force attached to the logical 'must' cannot be understood, however, unless we contrast it, furthermore, with the one attached to the moral ought, at the center of Brandom's Kantian framework. Thus, the second move consists in further distinguishing between two kinds of rules. Logical impossibilities and necessities belong to the domain of constitutive rules. As Descombes says, if the logical impossibility is characterized by "the impossibility of trying to do what is asserted impossible," this is because the action itself "can be understood and described only by reference to the constitutive rules defining it" (2007: 404). Consequently, the normative force of logic is different from that of practical rules. Indeed, as Descombes points out, a "constitutive rule is not a commandment (a law prescribing or forbidding an action)" (2007: 404): commandments belong to the domain of regulative rules, which are understandable only insofar as two intelligible alternatives are already there, 
independent of the rule, whereas constitutive rules leave open only one intelligible possibility, sorting out the contrary as unintelligible.

This is why Descombes goes as far as to say that constitutive rules are not prescriptive. What he means is that these rules do not say "what one ought to do (what one is obliged) to do" but "what there is and what there isn't (according to our institutions, our conventions)" (2007: 405). There is an interesting point here about the expressive power of normative vocabulary. Indeed, a constitutive rule seems to be characterized by the fact of authorizing the elimination of normative vocabulary: as Wittgenstein says in Zettel, instead of saying "one can't castle in draughts," we should just say "there is no castling in draughts" ( $\mathrm{Z}$, $\S 134)$. In this way, what seems to be a prescription is turned into a description: a description of a normative fact, however, implied by the constitutive rules, as opposed to the purely factual description presupposed by obligations and prohibitions. It is clear, therefore, that the translation from the imperative to the indicative only works for someone already knowing the game. As Descombes acknowledges, commenting some remarks of Wittgenstein in The Lectures on the Foundations of Mathematics, when explaining to someone the rules of our game we go back to the normative vocabulary, since we say precisely such things as: "Here the rule says you must turn; here you may go whichever way you like" (2007: 442). ${ }^{18}$

Opposed to the realm of natural regularities, the logical must is nonetheless opposed to obligations as constitutive rules are opposed to regulative rules. The latter points to an independently intelligible behavior as appropriate, sorting out the contrary as inappropriate: this is the most general genus of a host of different practical rules strategies, moral maxims, positive laws, etc. Constitutive rules are of a different nature, since here the rule enters into the very conditions of a meaningful action. This is the genus where we find an important kind of practical rules, "conventional necessities": now, as Descombes says, when we interpret conventional necessities and impossibilities as obligations and prohibitions "we simply lose sight of the meaning of the institution," since we "wrongly imagine an institution as a natural activity" that "men try to domesticate" by "imposing some restrictions to its free exercise" and we fail to understand "the constitutive or creative nature of rules when they function as rules of a game" (2007: 407-8).

21 If Brandom is not interested in social practices based on constitutive conventional rules creating a social world, it is because he thinks that this kind of "socially instituted norms" cannot be our model for understanding what he calls "conceptual norms": indeed, the latter "incorporate objective commitments," which contrasts with the error-free nature of conventional rules; to take Brandom's example, whatever "the Kwakiutl treat as an appropriate greeting gesture for their tribe, or a correctly constructed ceremonial hut, is one; it makes no sense to suppose that they could collectively be wrong about this sort of thing" (1994: 53). This means that in thinking of conceptual norms, Brandom has in mind descriptive concepts concerning the natural world, such as "mass" (1994: 53), which essentially require the distinction between what we take as a correct application and what is a correct application of them. As intuitive as the objectivity claim may be, it rests on a narrow conception of concepts which parallel the narrow conception of normativity we have just seen. 


\section{Kinds of Concepts}

22 In thinking of conventional necessities, Wittgenstein did not just want to give a logical reading of social conventions, but also a conventional reading of logic: he was not only explaining the meaning of social institution, but the social institution of meaning. As Descombes points out, in thinking of the specific nature of the 'logical must' through the game analogy Wittgenstein wanted, first and foremost, to reform traditional philosophical thinking about the nature of a priori concepts: his aim was to discard the implicit assimilation between a priori and a posteriori propositions, leading to a reading of logical propositions as stating "a priori facts concerning the world" (2007: 437). In place of this, Wittgenstein underlined the function of the logical must: the "necessity" of "es mu $\beta$," when added to a proposition, transforms it into a "norm of representation" (2007: 436) ruling out in advance facts that might contradict it. Thus, the distinction between constitutive and regulative rules, derived from the language game analogy, sheds light on the very nature of cognitive concepts. If there certainly are many ways of understanding Wittgenstein's conventionalism, ${ }^{19}$ the first step is to understand the very distinction between two kinds of conceptual norms.

Thus, if Wittgenstein has done something in philosophy after Kant is not just to criticize the regulist conception of rules, at the basis of Kant's semantics, but to clarify the different nature and content of concepts in light of the pluralist conception of rules we have just seen: whereas Kant still thought of categories as regulative rules applied to a recalcitrant nature, Wittgenstein constantly pointed out that the presuppositions of contentfulness, which he extended far beyond the categories of the understanding, are best understood if we see in them a system of constitutive rules. Far from contenting himself with the very general idea of concepts as rules, Wittgenstein articulated the difference between regulative descriptive concepts and constitutive normative concepts. This is the distinction between empirical and grammatical propositions that Wittgenstein very often clarified by reference to the function and nature of the negation. In the Philosophical Investigation, for instance, he explains how the sentence "I can't imagine the opposite of this" must be understood, when used in connection with such claims as "only I myself can know whether I am feeling pain": "Of course, here 'I can't imagine the opposite' doesn't mean: my powers of imagination are unequal to the task [compare with: swimming across the Atlantic]. These words are a defense against something whose form makes it look like an empirical proposition, but which is really a grammatical one" (PI, § 251). At the end of the paragraph Wittgenstein adds: "(Remark about the negation of an a priori proposition))." The general idea of a normative nature of concepts is first developed, in Wittgenstein, to understand the specific way in which a priori propositions rule the world by ruling empirical thought.

This is Wittgenstein's notion of grammar, as what cannot be contradicted without falling into meaningless speech. With grammatical propositions we have, to use Brandom's vocabulary, commitments one cannot fail to endorse, unless one still wants to think something. The right question concerning this kind of commitments cannot concern their entitlement. They are constitutive conceptual commitments placed, as such, beyond justification: being the condition of any kind of discursive practice, the question of their being justified or not is simply meaningless. Now, this central point of Wittgenstein's philosophy implies the refusal of the rationalist framework Brandom inherited from 
Kant: indeed, if there is a structural distinction between two types of conceptual norms, then meaning cannot be equated with inference, since the rational understanding displayed in the game of giving and asking for reasons through assertions presupposes another kind of understanding, which concerns the arbitrary conditions of rational understanding. What is perhaps less obvious is to consider this central point as the heart of Wittgenstein's pragmatism as an overcoming of classical rationalism. For this, it is necessary to see how Wittgenstein finally developed a new way of accounting for the distinction of conceptual norms based on his fundamental commitment to social practices.

\section{Conclusion: Wittgenstein's Anthropological Pragmatism}

The distinction of two conceptual norms sheds a new light on the function assigned by Wittgenstein to social practices. Indeed, Wittgenstein did not only distinguish norms implicit in practice from rules explicit in language, but looked for those social practices which incorporate the constitutive logical norms governing the use of regulative empirical rules in language: what social practices have to account for is, in the first place, the tacit conditions of meaningful linguistic exchange. This is the perspective he developed in On Certainty, in a way that is particularly interesting for contemporary debates on pragmatism, since, in the context of a confrontation with Moore on the skeptic's challenge about knowledge's claims, Wittgenstein clarified, as never before, the way in which social practices are the condition of rational activity. It is the pragmatist tactics elaborated in this text that I want to explain as a conclusion.

In order to appease the skeptical anxiety, without falling, like Moore, in its trap, Wittgenstein analyzes, in On Certainty, the ordinary functioning of assertions, especially the use of 'I know that.' As he says, this explicit propositional knowledge has to be seen as an answer to a "practical doubt" (OC, § 19), based on definite reasons: in "normal linguistic exchange" (OC, § 260) the expression "I know" expresses the readiness to give "compelling grounds" in favor of the assertion (OC, § 243). Now, the skeptical doubt transgresses this normal functioning of assertions, by asking reasons for any kind of commitment. A regress of justifications results, which forces Moore, and all other philosophers, in order to answer the challenge, to look for a special kind of self-evident knowledge: propositional and yet not justified by any reason. Against this bad foundationalist strategy, Wittgenstein answers by questioning the conditions of a meaningful doubt: "If you tried to doubt everything you would not get as far as doubting anything. The game of doubting itself presupposes certainty" (OC, §115). To be intelligible, a doubt presupposes the language in which it can be expressed: therefore, it presupposes the certainties presupposed by language. This is why a distinction must be made between the propositional knowledge expressed through assertions and its tacit conditions of possibility.

The view Wittgenstein explicitly endorses in On Certainty is that these conditions are fixed in and through action: "Giving grounds, however, justifying the evidence, comes to and end; - but the end is not certain propositions' striking us immediately as true, i.e., it is not a kind of seeing on our part; it is our acting, which lies at the bottom of the language game" (OC, § 204). The supposedly self-evident knowledge is, in fact, practical know-how, 
which does not follow the norms of propositional knowledge, since it governs this knowledge as a norm. Thus, at the fundamental level of practical certainties, one should not say "I know that," since this opens the unanswerable question of entitlement, but use some grammatical indicators, disqualifying the entitlement question in advance: "It is my unshakeable conviction that" (OC, § 103), "Nothing in the world will convince me of the opposite" (OC, § 380), "I can’t be making a mistake about it" (OC, §630), or simply "Dispute about other things; this is immovable" (OC, § 655). If action lies at the bottom of language, expressing some constitutive conceptual commitments on which the discursive practice rests, it is because practical know-how is the point of entry in language. The child does not learn first to think and say, through assertions, that things are thus-and-so, but "to react in such-and-such a way; and in so reacting it doesn't so far know anything. Knowing only begins at a later level" (OC, § 538). The relation between mind and world is not, to begin with, a cognitive one: what we first learn are ways of knowing how to do things with things. This means that experience is originally organized by an intentional behavior carrying with it the logical structure of the world. When an individual finally come to the linguistic game which consists in an exchange of assertions, a whole system is already established, turning around the fundamental distinction, established in and through practice, between logical and empirical propositions: grammar is already there, as the implicit structure of ordinary experience, the skeleton of the phenomena we talk and deal with.

In giving such a foundational role to practice Wittgenstein deeply changed his notion of grammar. ${ }^{20}$ On Certainty proposes a functional classification of concepts, which explains the force of the logical must by looking to the "peculiar logical role" played by some concepts in the "system of our empirical propositions" (OC, § 136). From this functionalist perspective, even apparently empirical propositions, such as 'I have two hands', can play the logical role of grammatical propositions. This is precisely what Wittgenstein understood thanks to the skeptical challenge and the bad answer of Moore. He thus developed a new conception of logical constitutive rules, structuring thought in the background: what counts is no more the content of the proposition, in any possible way, but its place and role in a hierarchical system structured by a complementary opposition, defined by a difference of "status" between propositions. If no proposition is intrinsically privileged within the system, this does not mean that our beliefs form a homogeneous system facing the tribunal of experience, as in Quine's pragmatism: the relation between the propositions can be "altered with time, in that fluid propositions hardened, and hard ones became fluid" (OC, § 96), but the system as such must make a structural distinction between propositions open to "test by experience" and those functioning as a "rule for testing" (OC, § 98). The internal organization of this intellectual system depends on practice, since the genetic primacy of the practical know-how fixes its basis. Yet this practice is, at the same time, social. The structural organization of experience in practice is learned in an active relation with an adult, considered as an authoritative expert: the active "trust" that is necessary for a language game to be possible at all (OC, § 509) derives from a first relation of trust from the child to some "authorities" (OC, § 493). Thus, by taking part in some bedrock practices, the individual swallows a whole shared "world-picture" (OC, §167). It is against this "inherited background" that he can distinguish between "true and false" (OC, § 94), since it is only on this basis that a meaningful exchange of assertions can take place, starting with a particular practical doubt: "the questions that we raise and our doubts depend on the fact that some 
propositions are exempt from doubts [...] like hinges on which those turn" (OC, § 341). This is why the hierarchical system coincides with the whole of social practices.

of course, just as we cannot separate the two halves of the system, we cannot separate bedrock social practices, which deposit the first layer of beliefs as constitutive conceptual commitments, from those linguistic social practices which enable us to play the rational game of doubts, questions and answers, through assertions. Wittgenstein describes, in a sketchy way, this progressive development of the system through a differentiated practical learning:

The child learns to believe a host of things. I.e., it learns to act according to these beliefs. Bit by bit there forms a system of what is believed, and in that system some things stand unshakeably fast and some are more or less liable to shift. What stands fast does so, not because it is intrinsically obvious or convincing; it is rather held fast by what lies around. (OC, § 144)

In order to understand this development, and the way in which the structural distinction within the intellectual system reflects a difference in social practices, we certainly need a detailed description of the discursive practice, such as Brandom's account of the game of giving and asking for reasons, considered as a further step after bedrock social practices. The place, meaning and functioning of such discursive practice must be deeply reconsidered once we see it through the lens of Wittgenstein's pragmatism. Indeed, if we take seriously the double distinction of norms and concepts as he finally elaborated it in On Certainty, we have to admit that a more complex account is needed: in order to fully understand discursive practice as the articulation of rational ought's we have to understand it against the background of socially instituted constitutive norms fixing the conditions of objectivity. A lot of substantive work is still needed to fully have social practices in mind.

\section{BIBLIOGRAPHY}

BOUVERESSE J., (1987), Le mythe de l'intériorité: expérience, signification et langage privé chez Wittgenstein, Paris, Minuit.

BRANDOM R., (1994), Making It Explicit: Reasoning, Representing and Discursive Commitment, Cambridge (Mass.), Harvard University Press.

BRANDOM R., (2002), Tales of the Mighty Dead: Historical Essays in the Metaphysics of Intentionality, Cambridge (Mass.), Harvard University Press.

BRANDOM R., (2011), Perspectives on Pragmatism: Classical, Recent and Contemporary, Cambridge (Mass.), Harvard University Press.

CONANT J. \& U. ZEGLEN (2002), Hilary Putnam: Pragmatism and Realism, London, Routledge.

DESCOMBES V., (2007), Le raisonnement de l'ours, Paris, Seuil.

BAKER G. P. \& P. M. S. HACKER, (1984), Skepticism, Rules and Language, Oxford, Blackwell.

HAugeland J., (1982), “Heidegger on Being a Person,” Nous 16. 
HAUGELAND J., (1998), Having Thought, Cambridge (Mass.), Harvard University Press.

KRIPKE S., (1982), Wittgenstein on Rules and Private Language: An Elementary Exposition, Cambridge, Harvard University Press.

MCDOWELL J., (2009), The Engaged Intellect: Philosophical Essays, Cambridge, Harvard University

Press.

MOYEL-SHARROCK D., (2004), Understanding Wittgenstein's On Certainty, New York, Palgrave

Macmillan.

PUTNAM H., (1995), Pragmatism: An Open Question, Oxford, Blackwell.

SELLARS W., (2007), In the Space of Reasons: Selected Essays of Wilfrid Sellars, Cambridge, Harvard University Press.

WILliams M., (1999), Wittgenstein, Mind and Meaning: Toward a Social Conception of Mind, London, New York, Routledge.

WITTGENSTEIN L., (1953), Philosophical Investigations, Oxford, Blackwell.

WITTGENSTEIN L., (1958), The Blue and Brown Books, Oxford, Blackwell.

WITTGENSTEIN L., (1967), Zettel, Oxford, Blackwell.

WITTGensteIn L., (1969), On Certainty, Oxford, Blackwell.

\section{NOTES}

1. For this strategy see, for instance, J. Bouveresse, "Le 'pragmatisme' de Wittgenstein" in Bouveresse (1987), and H. Putnam, “Was Wittgenstein a Pragmatist?," in Putnam 1995.

2. Brandom has first formulated this distinction in "Pragmatics and Pragmatism," Conant, Zeglen 2002. Putnam strongly criticized in his answer to Brandom his simplified view of the American pragmatism. Brandom has now developed a more complex account in Brandom 2011, to which I refer in what follows.

3. See R. Brandom, "From German Idealism to American Pragmatism - and Back," in Brandom 2011.

4. See W. Sellars, "Some reflections on language games," now in Sellars 2007.

5. See also Williams (1999), ch. 6, for a similar analysis.

6. See the passage quoted in McDowell (2009: 106).

7. For this regress argument in Brandom, see Brandom (1994: 21).

8. We also need "the teaching" (§ 197), as we will see.

9. For Brandom's discussion of Sellars, see Brandom (1994: 26).

10. See Kripke 1982.

11. As we will see below, the question is to know whether Wittgenstein shared Kant's conception of conceptual normativity or whether Brandom merges a general claim with a narrower concept of rules and concepts derived from Kant.

12. See Brandom (1994: 658), footnote 45.

13. See Baker, Hacker (1984: 42).

14. See Haugeland 1982, and Haugeland 1998.

15. See R. Brandom, "Some pragmatist themes in Hegel's Idealism," in Brandom (2002).

16. See Brandom's discussion of Pufendorf and Enlightenment contract theories in Brandom (1994: 47-52).

17. See Descombes 2007. 
18. Descombes quotes a passage from L. Wittgenstein, Lectures on the Foundations of Mathematics, Cambridge 1939, from the notes of R. G. Bosanquet, Norman Malcolm, Rush Rhees, and Yorick Smythies, edited by Cora Diamond, The University of Chicago Press, 1975, 241.

19. For instance, in developing Wittgenstein's view, Descombes comes curiously closer to the instrumentalist perspective of American pragmatists. Indeed, according to him, since logical norms fix the condition of cognitive activity, they cannot belong to the cognitive realm. They are a matter of decision: just as conventions depend ultimately on what is "desirable" (2007: 408), a priori representations are not justified "by their conformity to an (ideal) reality" but by our "different practical necessities," that is, by our "different needs" (2007: 443). This is a further and, in my view, wrong step, which is not necessarily implied by Wittgenstein's distinction between two types of conceptual norms.

20. The development of grammar in On Certainty through a pragmatist reading of hinge propositions is explained in detail by D. Moyal-Sharrock 2004.

\section{ABSTRACTS}

This paper clarifies why and how Wittgenstein's animating idea of social practices should be considered as expressing a fundamental pragmatist commitment.To this end, I do not take the retrospective perspective, which traces "pragmatism" back to the criteria of use fixed by the inventor of the word, C.S. Peirce, but rather replace Wittgenstein in the context of contemporary debates. I focus in particular on R. Brandom's attempt to understand Wittgenstein's second philosophy as belonging to an intellectual tradition from which his own rationalist pragmatism derives. A confrontation follows between Brandom and Wittgenstein, whose aim is to highlight the specific tactics of Wittgenstein's pragmatism as a refusal of Brandom's idealist rationalism. First, I present and defend R. Brandom's reading of Wittgenstein's argument on rule-following as a decisive clarification of the general idea of social practices. Second, I criticize Brandom's narrow Kantian framework, explaining why it prevents us from understanding Wittgenstein's conception of rules and concepts, and, therefore, of the very normativity of concepts. In light of the distinction between two kinds of conceptual norms, empirical and grammatical, I finally show, through a reading of On certainty, that the function assigned by Wittgenstein to social practices is to account for the conditions of possibility of conceptual contentfullness as expressed in rational activity.

\section{AUTHOR}

\section{FRANCESCO CALLEGARO}

École des Hautes Études en Sciences Sociales

fra.callegaro[at]gmail.com 